\title{
Effects of impurities and their redistribution during recrystallization of ice crystals
}

\author{
D. ILIESCU, I. BAKER \\ Thayer School of Engineering, Dartmouth College, Hanover, New Hampshire 03755-8000, USA \\ E-mail: ian.baker@dartmouth.edu
}

\begin{abstract}
In order to examine the effects of solutes on recrystallization and subsequent grain growth in ice, both doped and undoped ice single crystals were extruded through a $120^{\circ}$ equal-channel angular extrusion jig, in order to impart a large shear strain ( 1.15). Upon subsequent annealing at $-3^{\circ} \mathrm{C}$, the original single crystals recrystallized, in most cases to a new single crystal with a different orientation. Increasing the solute concentration (for $\mathrm{H}_{2} \mathrm{SO}_{4}$ to $\sim 200-300 \mathrm{ppb}$, and for $\mathrm{NaCl}, \mathrm{KCl}$ and $\mathrm{MgSO}_{4}$ to $>5 \mathrm{ppm}$ ) was found to significantly retard the growth and possibly, for $\mathrm{H}_{2} \mathrm{SO}_{4}$-doped ice, the nucleation of new grains in the strained ice single crystals. This is indicative of how soluble impurities can retard grain growth in ice cores. It was also found that the migrating grain boundaries surrounding the newly formed grains contained large concentrations of impurities, often observed as filaments. These could have formed by the grain boundaries sweeping up impurities from the lattice into the boundary or by their diffusion to the boundary - mechanisms whereby impurities could be concentrated into the grain boundaries in ice cores - although the latter mechanism seems unlikely since it would require very high diffusion rates.
\end{abstract}

\section{INTRODUCTION}

Both the concentrations and microstructural locations of impurities in ice cores can have significant impacts on the mechanical properties, recrystallization behavior, grain growth, electrical conductivity, diffusion and texture development of ice. The microstructural location of impurities can also influence their post-depositional movement in ice cores (Nye, 1998), possibly affecting the interpretation of the icecore record for paleoclimate reconstruction.

By examining aluminum-coated ice specimens from Dolleman Island, Antarctica, using energy-dispersive X-ray microanalysis (EDS) in a scanning electron microscope (SEM), Wolff and others (1988) first showed that, although the total concentrations of impurities in natural ice are low (Legrand and Mayewski, 1997), the concentrations of impurities in a triple junction could be high. This concentration of impurities in triple junctions was subsequently

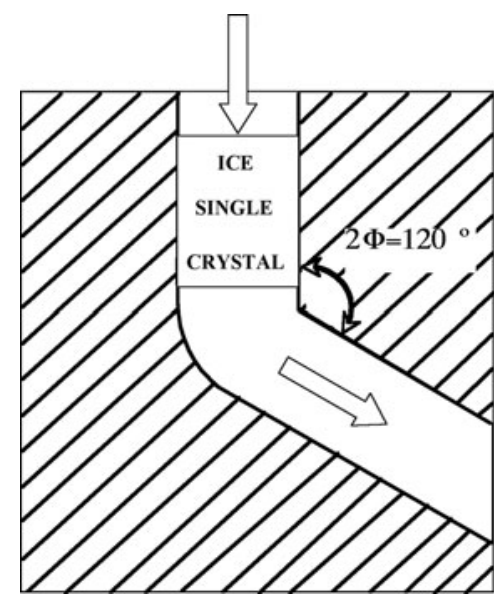

Fig. 1. Schematic of an ice single crystal being extruded through an equal-channel angular extrusion (ECAE) jig with a rounded corner. For $2 \phi=120^{\circ}$ the theoretical plastic strain imparted is 1.15 . The arrows show the extrusion direction. confirmed by Fukazawa and others using Raman spectroscopy (Fukazawa and others, 1998). Later, Cullen and Baker (2001), using EDS in a SEM on uncoated ice from the Greenland Ice Sheet Project 2 (GISP2) ice core showed that impurities could be concentrated along the grain boundaries as well as in the triple junctions. The latter observation was confirmed in a number of subsequent studies on ice-core specimens from both Greenland and Antarctica (Cullen and Baker, 2000, 2001, 2002; Baker and Cullen, 2002, 2003; Barnes and others, 2002a, b, 2003; Baker and others, 2003, 2005; Obbard and others, 2003a, b, 2006a, b; Obbard and Baker, 2007).

One question that arises from these observations is how the impurities become concentrated in the grain boundaries and triple junctions since, in the snow from which the ice forms, the impurities could be spread throughout the snowflake, possibly concentrated in the center of the snowflake when the snowflake was nucleated (Kumai and Francis, 1962; Libbrecht, 2005), or perhaps covering its surface if the snowflake scavenged impurities from the atmosphere during its descent. Diffusion to both the grain boundaries and triple junctions in the ice in order to lower the free energy of the system could be one mechanism through which concentration of impurities occurred.

Here we show through experiments on laboratory-grown ice single crystals doped with some commonly occurring impurities found in polar ice that grain boundaries sweeping through the ice during recrystallization can also be responsible for concentrating impurities in the grain boundaries. We also demonstrate that impurities retard grain boundary migration and, possibly, nucleation of recrystallization, indicating a role for impurities in controlling the grain size in polar ice.

\section{EXPERIMENTAL PROCEDURE}

Ice single crystals were grown by unidirectionally freezing either distilled water or a solution of sulfuric acid, magnesium sulfate, potassium sulfate or sodium chloride 

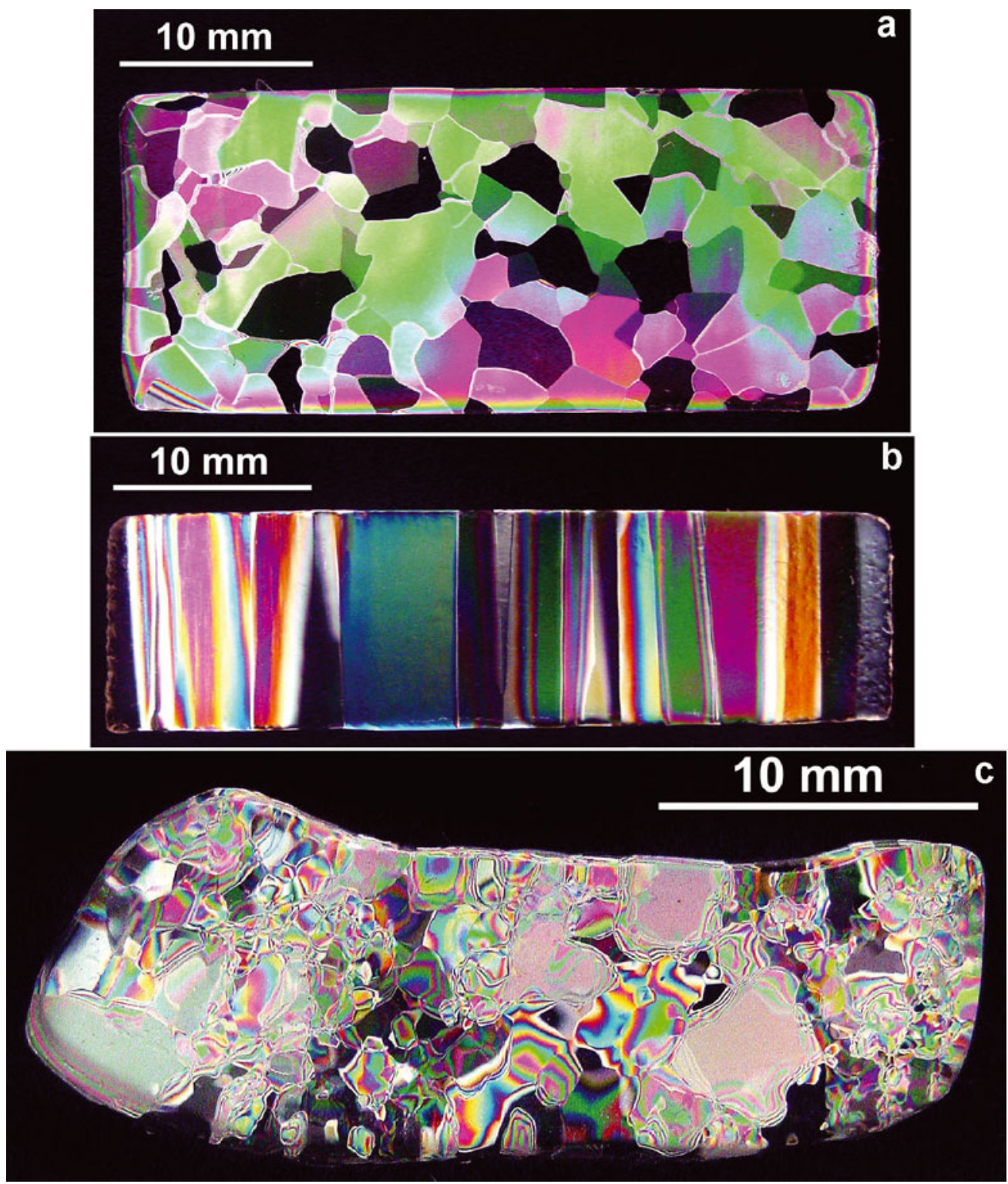

Fig. 2. Polycrystalline specimen of freshwater columnar S2 ice deformed using ECAE at $-3^{\circ} \mathrm{C}$ and subsequently annealed at the same temperature for 30 hours. (a, b) Horizontal (a) and vertical (b) thin sections photographed in polarized light showing the microstructure of the stock from which the billet was produced. (c) Photograph taken in polarized light 30 hours after deformation showing the recrystallized microstructure. Note the small newly formed crystals.

of various concentrations in distilled water over a period of 7-10 days. While dopants depress the freezing point of water, at the concentrations used in this study (up to a few ppm) the effect is negligible. Using the same method, columnar-grained ice with the basal plane perpendicular to the direction of the columns - so-called S1 ice (Michel and Ramseier, 1971) - was also produced. Undoped S2 polycrystalline ice (Michel and Ramseier, 1971), where the $C$ axes are essentially perpendicular (i.e. $90 \pm 8^{\circ}$ ) to the longitudinal axes of the columnar-shaped grains and randomly oriented within the horizontal plane of the parent puck, was also grown according to the procedure described by Iliescu (2000).

Since the dopants are partially rejected from the ice during crystal growth, the impurity concentration in the single crystals at the end of the freezing process is significantly lower than the concentration in the water from which they grow. Moreover, we noted that concentration of impurities in these relatively large single crystals (some over
$1 \mathrm{~kg}$ ) varied not only along the growth direction, as expected, but also in the horizontal plane.

To produce the final $10 \mathrm{~mm} \times 10 \mathrm{~mm} \times 30 \mathrm{~mm}$ cuboidal specimens required for the experiments, we started by isolating a set of large single crystals and dividing these into rough prismatic specimens about $15 \mathrm{~mm} \times 15 \mathrm{~mm} \times 60 \mathrm{~mm}$. After a fairly large number of such specimens was produced, the length of each specimen was reduced to $30 \mathrm{~mm}$ by removing roughly $15 \mathrm{~mm}$ from either side. The sides of each ice prism were then shaved flat with a clean razor blade to produce the final specimen. The ice and the shavings from each specimen were carefully collected, melted in a clean tube and the concentration measured. Based on these measurements, the specimens were separated into concentration bins. However, the solute concentrations mentioned throughout this paper are not bin concentrations. They are concentrations measured by melting the actual ice specimen (or pieces if SEM sample preparation was necessary) after the completion of the 


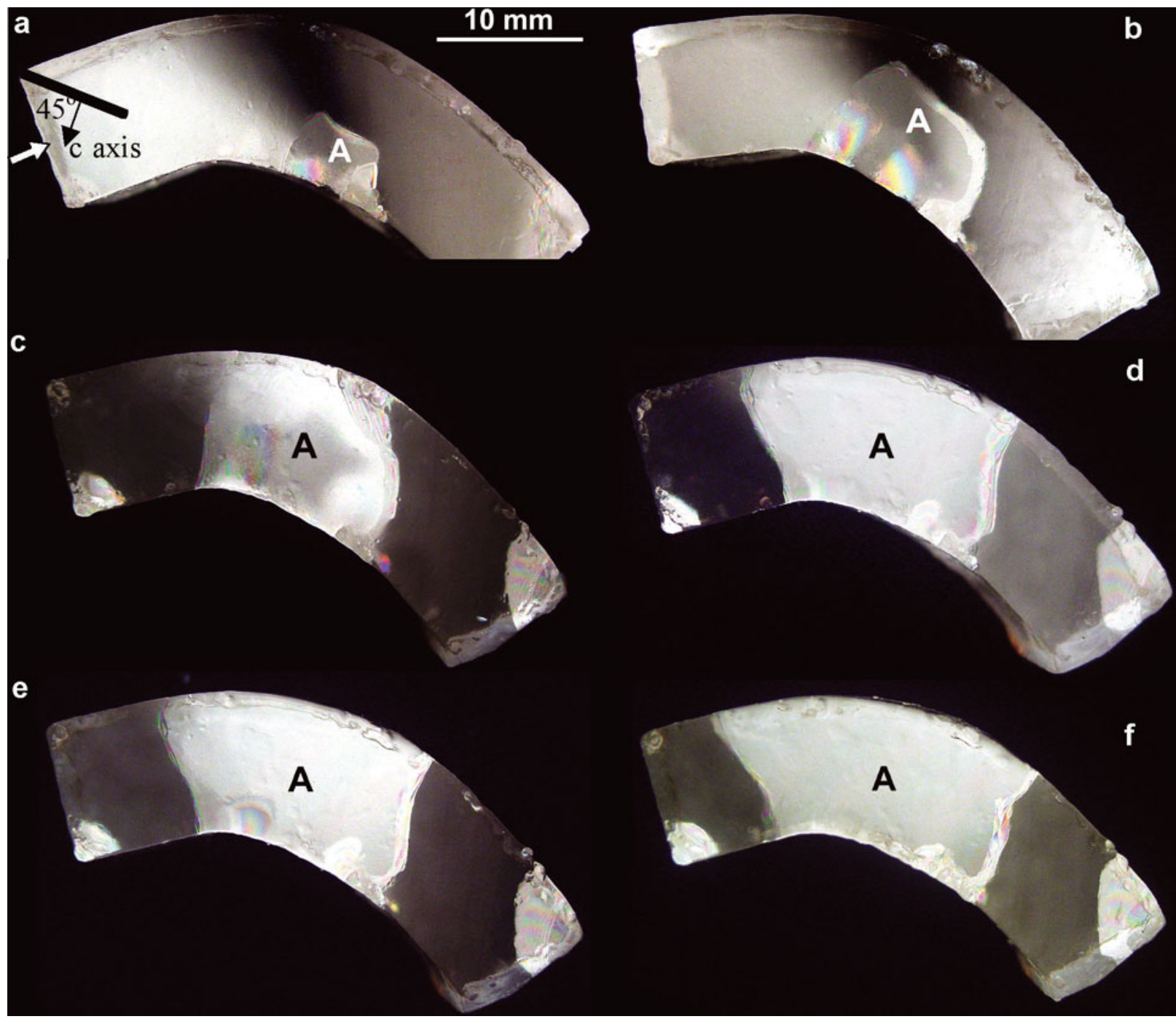

Fig. 3. Sequence of photographs taken in polarized light showing a freshwater single crystal with the basal plane oriented at $45^{\circ}$ with respect to the extrusion axis deformed using ECAE at $-3^{\circ} \mathrm{C}$. After deformation the specimen was annealed at the same temperature for 68 hours. The time intervals indicate annealing time. The images show the growth of a newly formed crystal (marked A) inside the original matrix.

experiment. The sulfuric acid concentration was measured using a $\mathrm{pH}$ meter, and the magnesium was measured using an electrode sensitive to magnesium ions. The concentrations of the $\mathrm{KCl}$ and $\mathrm{NaCl}$ were both determined with a conductivity probe. In all cases, the probes were calibrated using a set of standards on either side of the expected concentration range.

Primary recrystallization and subsequent grain boundary migration were investigated using the $10 \mathrm{~mm} \times 10 \mathrm{~mm} \times$ $30 \mathrm{~mm}$ cuboidal specimens mentioned above. They were subjected to large plastic shear strains imparted during slow extrusion through an equal-channel angular extrusion (ECAE) jig (Segal and others, 1981) with $2 \phi=120^{\circ}$ (see Fig. 1). The extrusion was carried out under a constant load of $1.7 \mathrm{~kg}$ wt over a period of $4-6$ hours at $-3 \pm 0.2^{\circ} \mathrm{C}$. As shown both theoretically (Segal, 1995; Iwahashi and others, 1996) and experimentally (Wu and Baker, 1997), extrusion with the rounded corner jig produces a shear strain of the order of unity ( 1.15). In some cases, the specimen did not fully extrude through the ECAE jig. After extrusion the specimens were 'annealed' at $-3 \pm 0.2^{\circ} \mathrm{C}$ for up to 90 hours in order to study the effects of the impurities on recrystallization and subsequent grain boundary migration.
In initial experiments, attempts were made to extrude undoped ice single crystals with the basal plane oriented perpendicular to the initial extrusion direction. For this orientation, the resolved shear stress on the basal slip systems $\langle 1120\rangle(0001)$ is zero. All these undoped ice specimens cracked. For subsequent successful extrusions on undoped ice single crystals, the basal planes were oriented at $45^{\circ}$ to the direction of the applied load. The polycrystalline S2 columnar-grained undoped ice was also successfully extruded through the jig.

Ice doped either with sulfuric acid at 70-170 ppb or with sodium chloride, potassium chloride or magnesium sulfate doped at 1-10 ppm was used to study the effects of solutes on the nucleation and growth of new grains. For these doped crystals, extrusion was performed with the basal plane perpendicular to the initial extrusion axis. That the doped crystals could be extruded in this orientation while the undoped crystals could not is indicative of their greater ductility, a feature previously noted in sulfuric acid doped ice single crystals (Trickett and others, 2000; Iliescu and others, 2003).

The occurrence of new grains in the extruded and annealed ice was studied by examining the ice specimens 


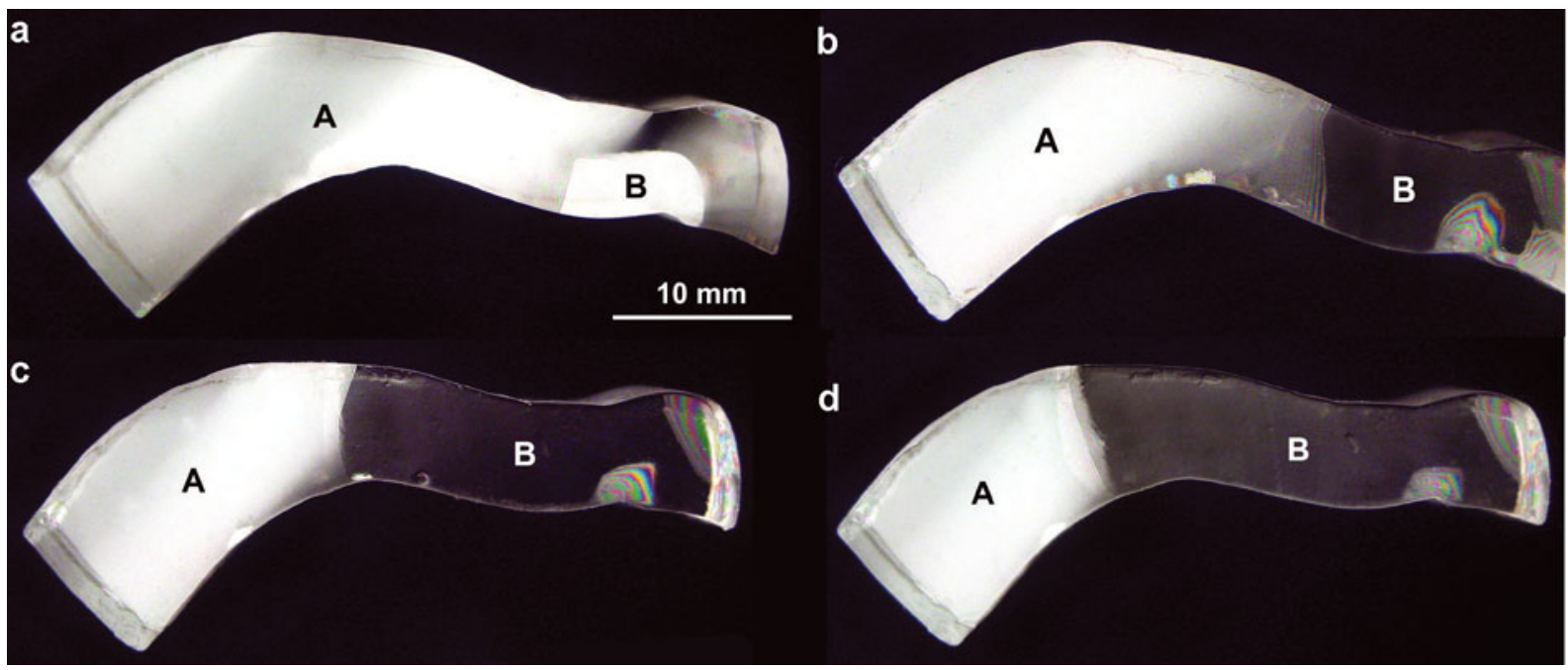

Fig. 4. $\mathrm{NaCl}$-doped specimen $(3 \mathrm{ppm})$ subjected to ECAE at $-3^{\circ} \mathrm{C}$. The basal plane is perpendicular to the extrusion axis. After deformation the specimen was annealed at the same temperature for 28 hours. The time intervals indicate annealing time. Sequence of photographs in polarized light showing the growth of a newly formed crystal (marked B) and the progressive reorientation of the original lattice (marked A).

optically between crossed polarizers. The chemistry of some grain boundaries was examined by cutting grain boundaries, optically observed, out of the specimen and examining them uncoated at $\sim-100 \pm 5^{\circ} \mathrm{C}$ using a JEOL 5310 low-vacuum SEM, equipped with a Princeton Gamma Tech. IMIX EDS system utilizing a pure germanium, aluminum-coated polyimide thin-window detector. The SEM was operated at $10 \mathrm{kV}$, and secondary electron imaging was used. Further details of the SEM examination and specimen preparation can be found elsewhere (Cullen and Baker, 2001, 2002; Baker and others, 2003).

\section{RESULTS AND DISCUSSION}

Figure $2 \mathrm{a}$ and $\mathrm{b}$ show photographs of horizontal and vertical thin sections of the microstructure of the stock from which the specimen of polycrystalline S2 columnar-grained ice was produced. Figure 2c is an image taken 30 hours after extrusion through the ECAE jig at $-3{ }^{\circ} \mathrm{C}$ showing the recrystallized microstructure. Note the multitude of smaller newly formed crystals in this originally polycrystalline specimen.

Figure 3 shows a sequence of photographs taken in polarized light showing a $45^{\circ}$-oriented undoped ice single crystal that had been extruded at $-3^{\circ} \mathrm{C}$ and then annealed at the same temperature for up to 68 hours. The specimen is bent since it did not completely extrude through the jig. Surprisingly for such a large imparted shear strain, only three new grains nucleated, one of which (labeled A) grew to consume half the original crystal. This feature of only one or very few new crystals nucleating was a common trait of many of the single-crystal experiments regardless of whether the ice was doped or not.

Figure 4 shows photographs of an ice single-crystal specimen doped with $3 \mathrm{ppm} \mathrm{NaCl}$ subjected to extrusion through the ECAE jig at $-3^{\circ} \mathrm{C}$ with the basal plane oriented perpendicular to the extrusion axis. After deformation the specimen was held at the same temperature for 28 hours. The sequence of photographs shows a single newly nucleated crystal (labeled B) consuming the original crystal (labeled A). A single new crystal consuming the original single crystal during annealing after extrusion was the most commonly observed result from these experiments.

Single crystals of various concentrations of $\mathrm{NaCl}$ were studied and it was noted that crystals doped with more than $\sim 5$ ppm exhibited few recrystallized grains. In total, five more highly $\mathrm{NaCl}$-doped specimens and one more highly $\mathrm{KCl}$-doped specimen exhibited a virtually identical behavior characterized by the formation, primarily in the tip region, of one or two small recrystalized grains (relative to the size of the specimen), during a short-lived initial growth period. The specimens were observed for up to 48 hours, and no other microstructural changes were noted during this time. This behavior is in agreement with the observations of Nasello and others (2007) on lightly KCl-doped bicrystal specimens. They reported that grain boundary mobility decreased by about one order of magnitude when the solute concentration was increased from $0.02 \mathrm{ppm}$ to $0.2 \mathrm{ppm}$. For example, Figure 5 shows a specimen doped with $6 \mathrm{ppm}$ $\mathrm{NaCl}$ that was extruded at $-3{ }^{\circ} \mathrm{C}$ and annealed for 24 hours. The newly formed crystals grew very little after the first 3 hours of annealing.

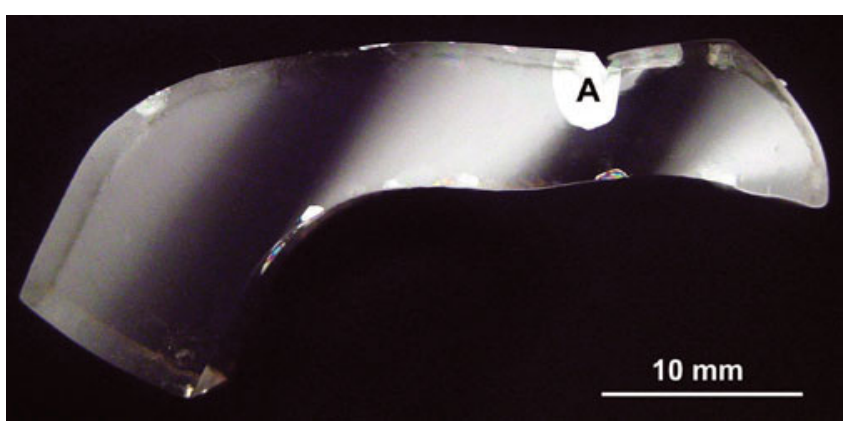

Fig. 5. $\mathrm{NaCl}$-doped specimen (6ppm) subjected to ECAE at $-3^{\circ} \mathrm{C}$ and subsequently annealed at the same temperature. Basal plane perpendicular to the extrusion axis. Photograph taken in polarized light 24 hours after deformation. Single crystals doped with more than $\sim 5$ ppm salt exhibited very few recrystallized grains. Upon annealing, the newly formed crystals grew little during the first 3 hours and remained virtually unchanged after that. 


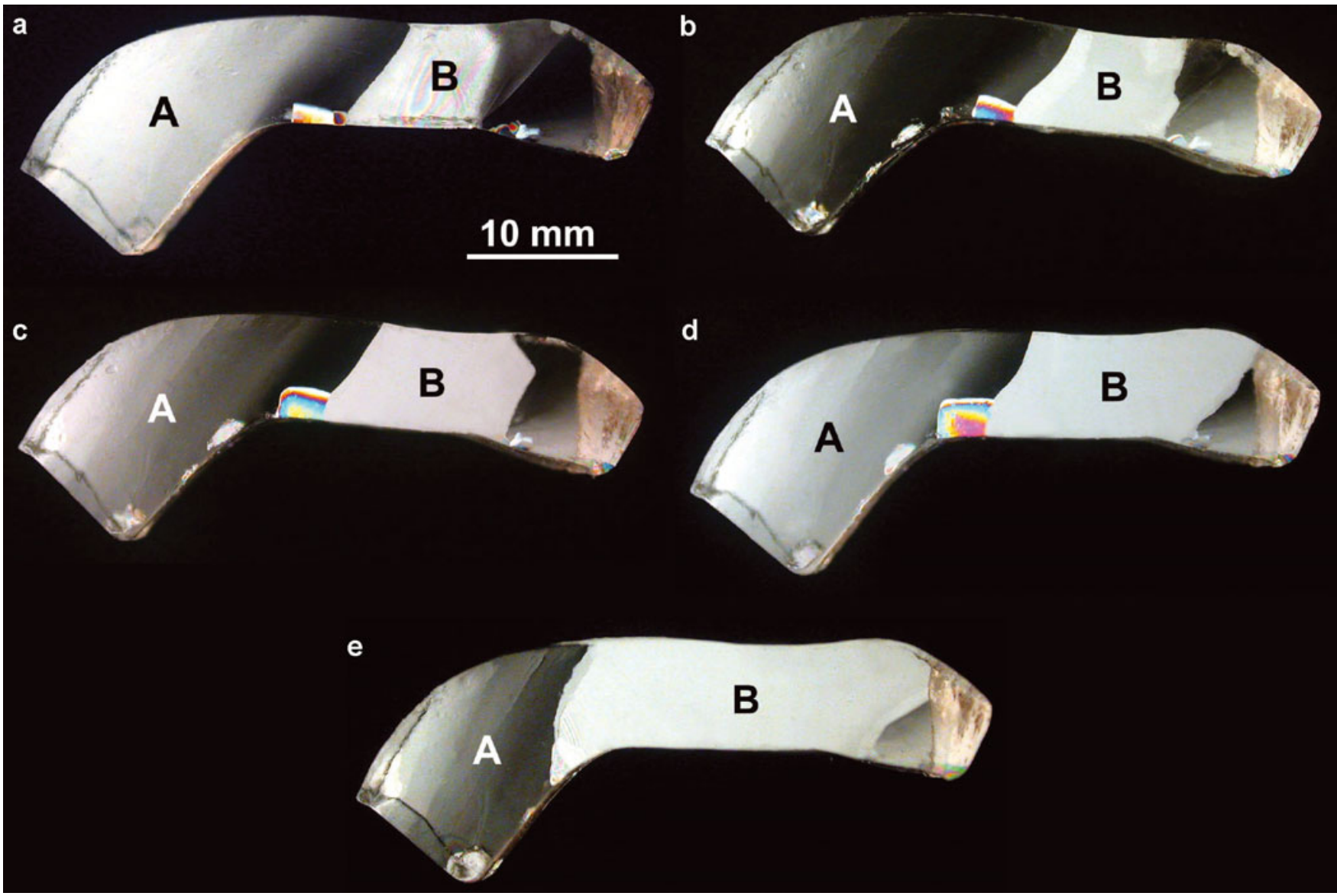

Fig. 6. $\mathrm{MgSO}_{4}$-doped specimen $(0.5 \mathrm{ppm})$ subjected to ECAE at $-3{ }^{\circ} \mathrm{C}$ followed by annealing at the same temperature. The basal plane was initially perpendicular to the extrusion axis. Photographs taken in polarized light after annealing for the indicated time intervals. Note the substantial growth of the newly formed crystal B. The original single crystal is marked A.

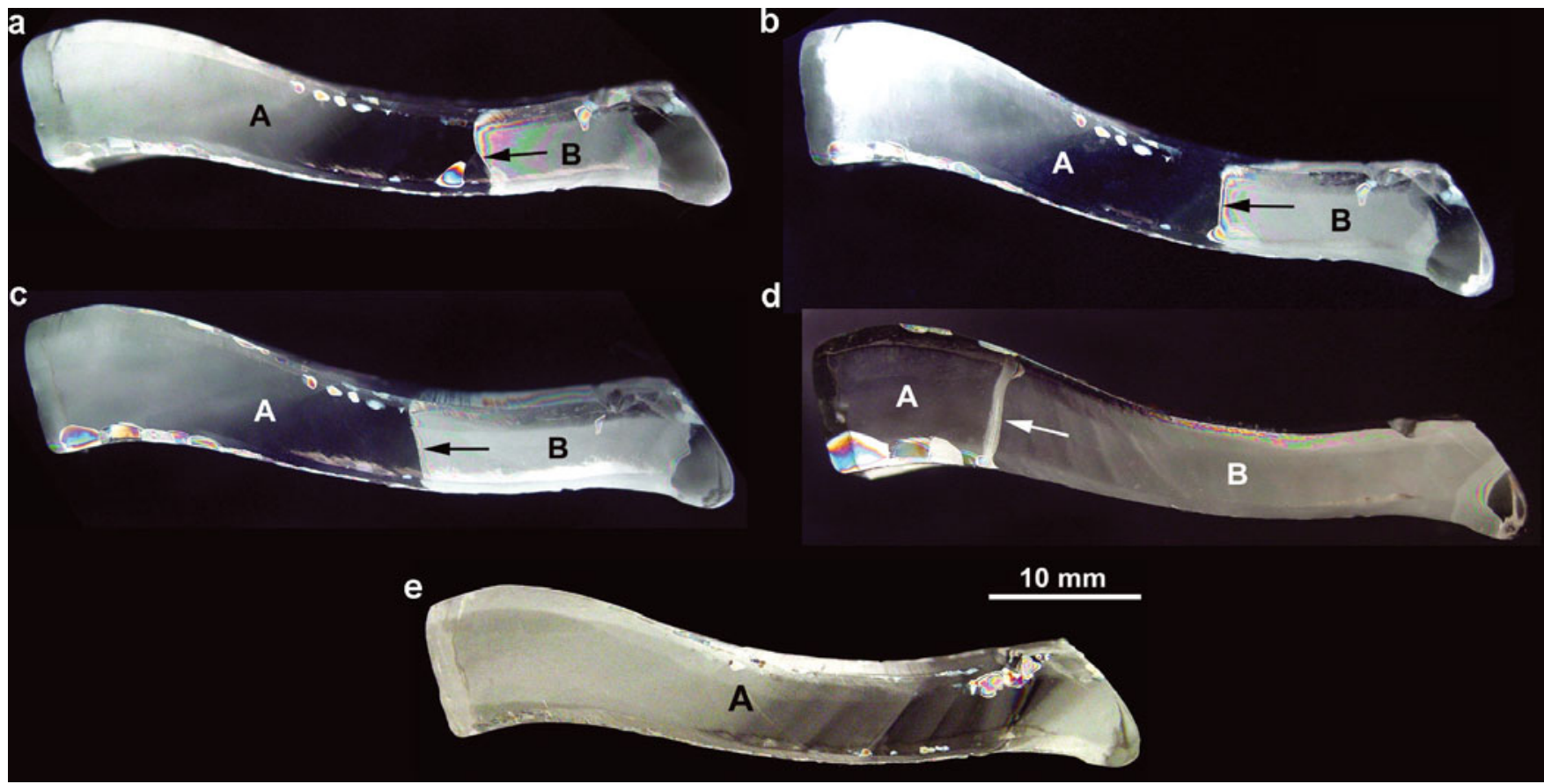

Fig. 7. $\mathrm{H}_{2} \mathrm{SO}_{4}$-doped specimen $(0.09 \mathrm{ppm})$ subjected to ECAE at $-3^{\circ} \mathrm{C}$. The basal plane was initially perpendicular to the extrusion axis. After deformation the specimen was annealed at the same temperature for 92 hours. The time intervals indicate annealing time. The photographs, taken in polarized light, show a clearly defined recrystallized grain (marked B) after 18 hours. The highly mobile grain boundary (arrowed) between the newly formed crystal B and the original single crystal A sweeps along the deformed specimen, progressively reorienting the original lattice. 


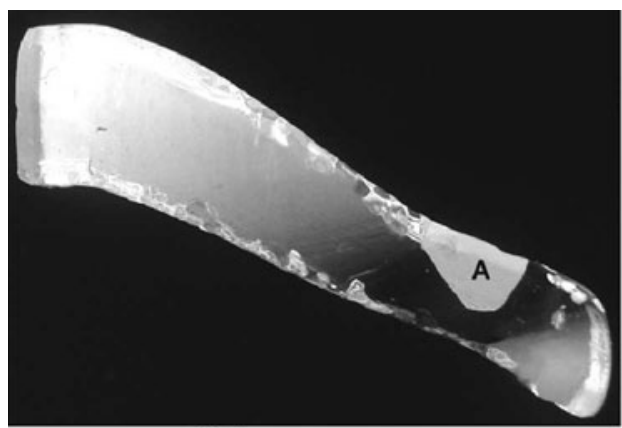

3 hours

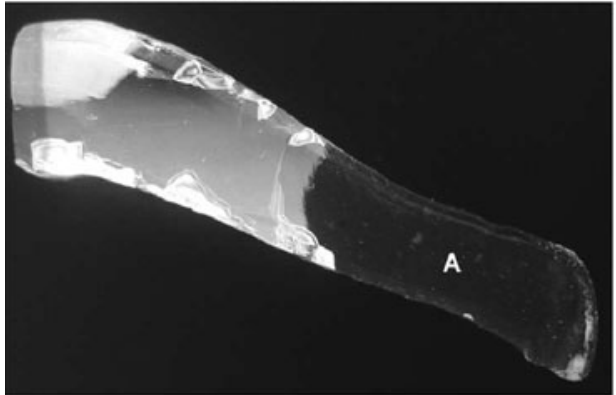

20 hours

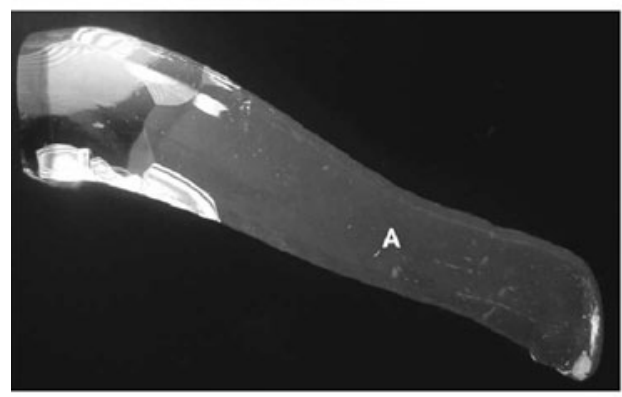

48 hours

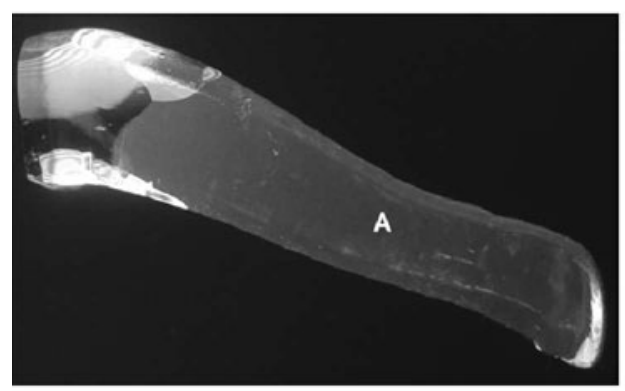

56 hours
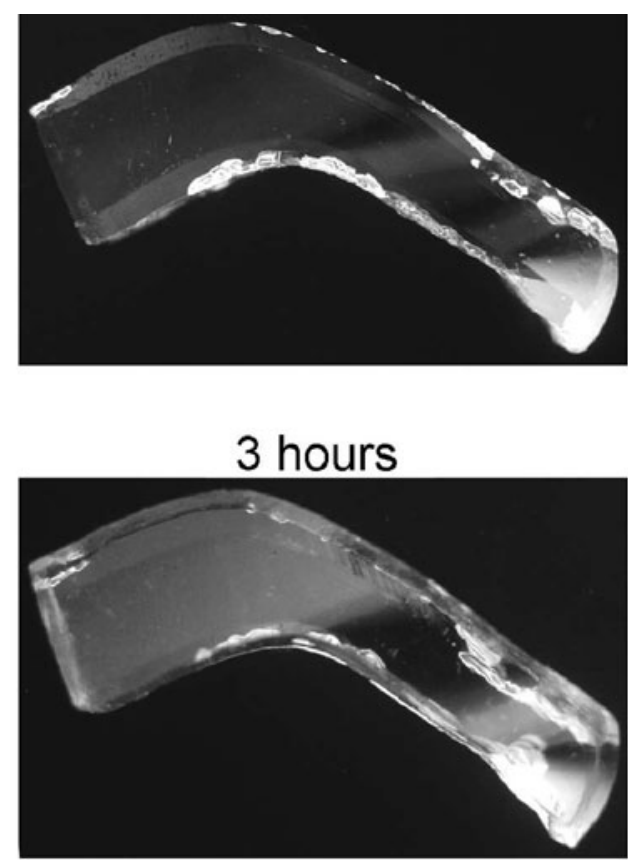

20 hours

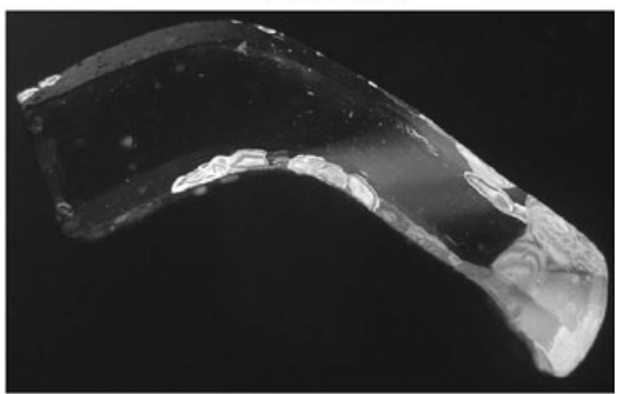

48 hours

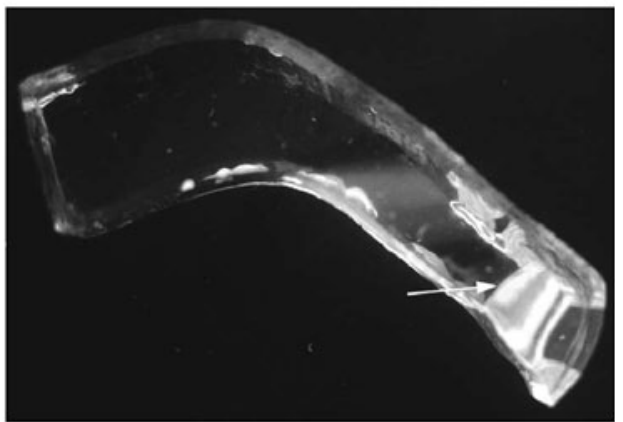

67 hours

Fig. 8. Photographs showing the effect of sulfuric acid on primary recrystallization and grain boundary migration after processing through an ECAE jig. The concentration of sulfuric acid was $70 \mathrm{ppb}$ in the specimen on the left and $170 \mathrm{ppb}$ in the specimen on the right. ' $\mathrm{A}$ ' marks a newly formed grain in the 70 ppb-doped specimen. The arrow (bottom right) points to an inclined grain boundary. Note the difference in appearance between the two crystals at comparable times and the much more rapid migration of the newly formed grain boundary in the less doped crystal (left).

For low dopant concentration, both $\mathrm{MgSO}_{4}$-doped specimens and $\mathrm{H}_{2} \mathrm{SO}_{4}$-doped specimens showed similar behavior to the $\mathrm{NaCl}$-doped ice (Figs 6 and 7). Figure 6 shows a new grain (labeled $\mathrm{B}$ ) in a 0.5 ppm $\mathrm{MgSO}_{4}$-doped ice single crystal that had been extruded and annealed at $-3^{\circ} \mathrm{C}$; this crystal grew and consumed most of the original crystal (labeled A). Similarly Figure 7 shows an ice singlecrystal specimen doped with $0.09 \mathrm{ppm} \mathrm{H}_{2} \mathrm{SO}_{4}$ that had been subjected to ECAE, and then annealed at $-3^{\circ} \mathrm{C}$. After 18 hours, a clearly defined recrystallized grain (marked $B$ ) is shown which sweeps through the original crystal (labeled A) during subsequent annealing.

One key difference observed between the effect of $\mathrm{H}_{2} \mathrm{SO}_{4}$ and the other dopants was that only about $170 \mathrm{ppb} \mathrm{H}_{2} \mathrm{SO}_{4}$ were necessary to significantly retard recrystallization of the extruded ice single crystals (three specimens doped with 130, 160 and $170 \mathrm{ppb} \mathrm{H}_{2} \mathrm{SO}_{4}$ ), whereas several ppm of the other dopants, i.e. an order of magnitude greater, was required to prevent or significantly retard recrystallization. This is illustrated in Figure 8 in which the concentration of 


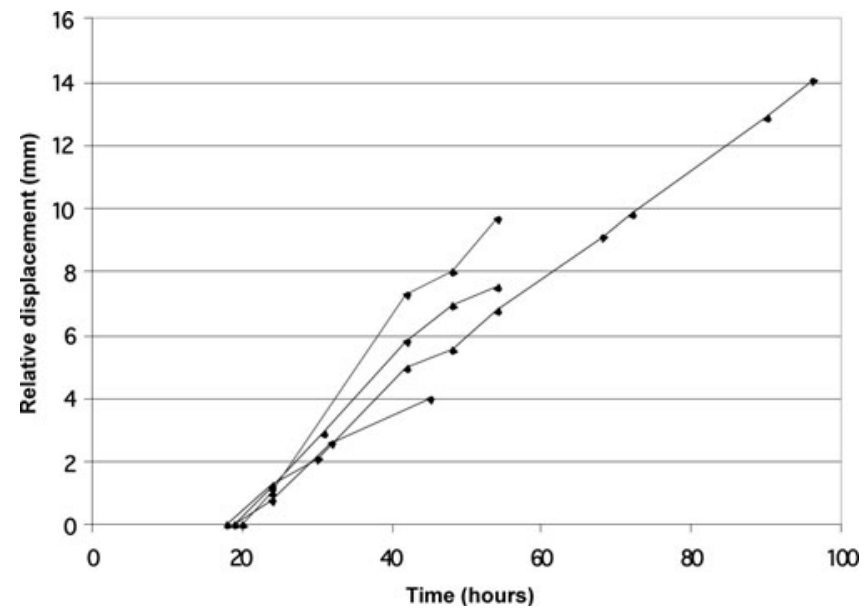

Fig. 9. Graph showing the displacement rate of mobile grain boundaries in $\mathrm{H}_{2} \mathrm{SO}_{4}$-doped ice single crystals (0.09 ppm) subjected to deformation using ECAE at $-3^{\circ} \mathrm{C}$ and annealed for various lengths of time at the same temperature.

$\mathrm{H}_{2} \mathrm{SO}_{4}$ was $70 \mathrm{ppb}$ in the specimen on the left and $170 \mathrm{ppb}$ in the specimen on the right. ' $A$ ' marks a newly formed grain in the $70 \mathrm{ppb}$-doped specimen. The arrow (bottom right) points to an inclined grain boundary. While part of the latter specimen did not extrude through the ECAE jig, the part that did suffered the same shear strain as the $70 \mathrm{ppb}$ specimen and thus had the same driving force for recrystallization and grain growth. Note the difference in appearance between the two crystals at comparable times, and the much more rapid nucleation of new grains and migration of the newly formed grain boundary in the less doped crystal (left). Thus, it is evident that the presence of sulfuric acid in relatively small concentrations retards both recrystallization and grain growth in ice, i.e. a similar effect to solutes in metals.

The difference between the effect of $\mathrm{KCl}, \mathrm{NaCl}$ and $\mathrm{MgSO}_{4}$ on the one hand and $\mathrm{H}_{2} \mathrm{SO}_{4}$ on the other may be due to the extra protons $\left(\mathrm{H}^{+}\right)$supplied by the sulfuric acid. These allow the hydrogen bonds to reorient more readily, thus increasing the mobility of the dislocations (Glen, 1968; Whitworth and others, 1976; Whitworth, 1980). In the concentration range noted above ( $\ll 1 \mathrm{ppm})$, the dislocation mobility will increase with increasing $\mathrm{H}_{2} \mathrm{SO}_{4}$, and consequently, following deformation, the more highly $\mathrm{H}_{2} \mathrm{SO}_{4}-$ doped specimens might undergo significant recovery rather than minimize the stored strain energy through the creation of new stress-free grains such as in the case of $\mathrm{NaCl}$ and lightly doped $\mathrm{H}_{2} \mathrm{SO}_{4}$ ice. One would expect similar effects from doping with other acids such as nitric acid and hydrochloric acid.

The results, that relatively low levels of impurities can inhibit grain boundary migration in ice, are in accord with a number of observations made on ice cores where an inverse correlation has been observed between the grain size and the impurity concentration (Gow and Williamson, 1976; Duval and Lorius, 1980; Alley and others 1986; Lipenkov and others, 1989; Thorsteinsson and others 1995, 1997; Alley and Woods, 1996; de la Chapelle and others, 1998; Obbard and Baker, 2007). Further, de la Chapelle and others (1998) noted that not only did the grain growth rate decrease as the concentration of sodium ions increased in core from Dome C, East Antarctica, but above a particular sodium ion level, grain growth largely stopped.

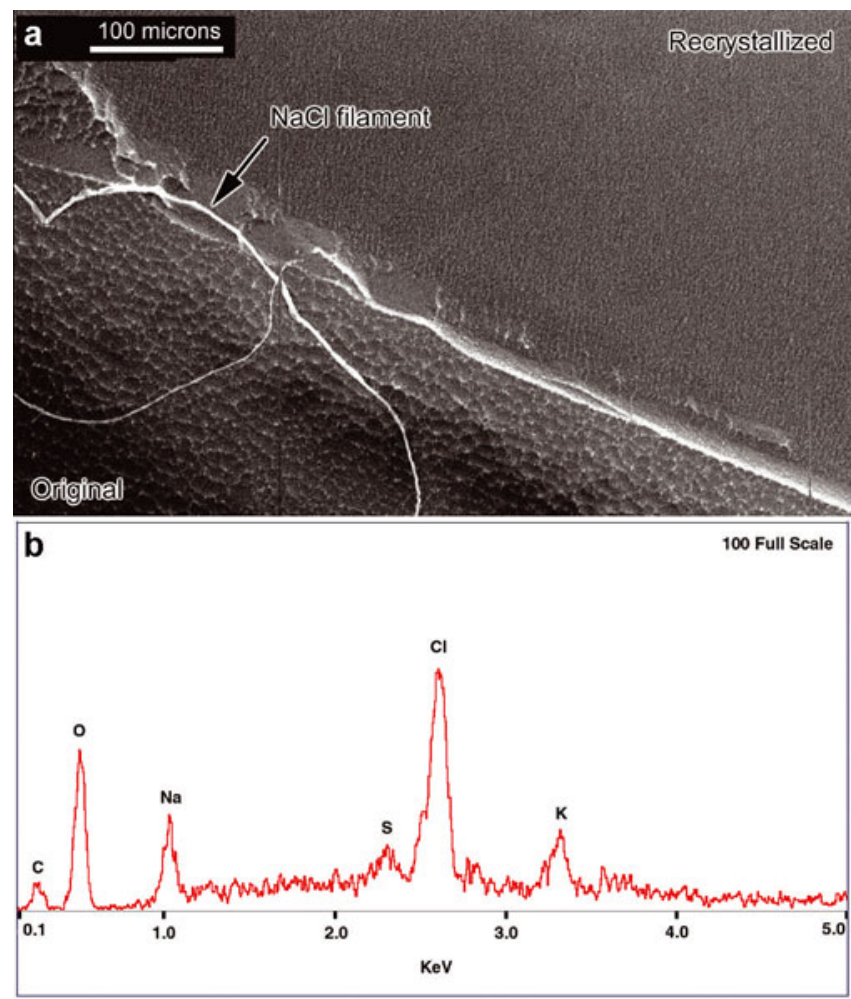

Fig. 10. (a) SEM image showing impurity filaments on a boundary between the original single crystal and a newly recrystallized grain in heavily $\mathrm{NaCl}$-doped specimen (doping level $>5 \mathrm{ppm}$ ). (b) EDS spectrum collected from the filament in (a). The $\mathrm{O}$ peak arises from the ice, and the $\mathrm{C}$ is probably contamination. $\mathrm{K}$ and $\mathrm{S}$ are probably from impurities in the $\mathrm{NaCl}$ dopant. Full scale is 100 counts.

The grain boundary migration rates were measured in several of the $0.09 \mathrm{ppm} \mathrm{H}_{2} \mathrm{SO}_{4}$-doped ice single crystals by measuring the distance that the center of a grain boundary migrated in a given time. The results are shown in Figure 9. The measured grain boundary migration rates are from $6 \times$ $10^{-8}$ to $9 \times 10^{-8} \mathrm{~m} \mathrm{~s}^{-1}$. This is comparable to the grain boundary migration rate measured in rolled and then annealed copper single crystals (Haessner and Hofmann, 1978).

In order to determine whether recrystallization and grain growth can redistribute solutes in ice, several specimens containing newly recystallized grain boundaries were examined in the SEM. Unlike the acid-doped specimens which never exhibited filaments, the salt-doped specimens, especially those with a high level of dopant, invariably produced filaments. These filaments exhibit some cohesiveness because they can be peeled off the sublimating grain boundary and twisted using the electron beam of the SEM. Figures 10 and 11 show SEM images in which impurity filaments are present along the grain boundaries in specimens heavily doped (doping level greater than approximately $5 \mathrm{ppm}$ ) with either $\mathrm{NaCl}$ or $\mathrm{KCl}$. EDS showed that these filaments consisted of the salts with which the ice was doped. (Note that $\mathrm{K}$ appears to be an impurity in $\mathrm{NaCl}$ and that $\mathrm{Na}$ is an impurity in $\mathrm{KCl}$.) Cullen and Baker (2001) discuss filament formation in natural ice.

Figure 12 shows the accumulation of $\mathrm{NaCl}$ at the interface between the recrystallized lattice and the original unrecrystallized part of the crystal in a more heavily doped specimen. That the grain boundaries in the recrystallizing grains sweep up the soluble impurities from the lattice into 


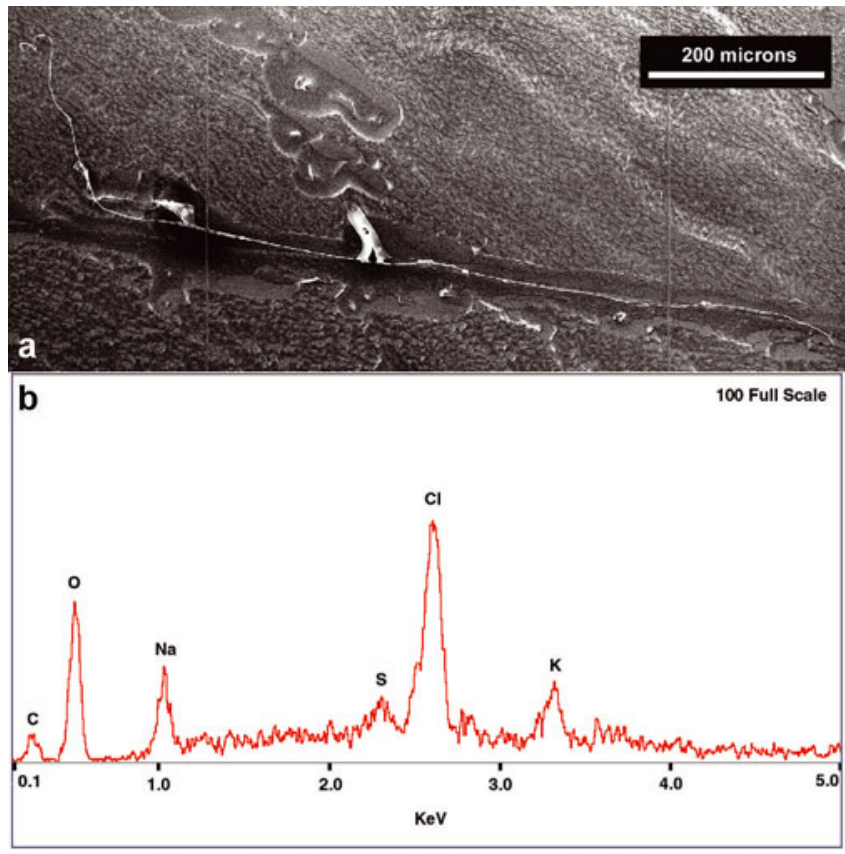

Fig. 11. (a) SEM image showing impurity filament on a grain boundary in heavily $\mathrm{KCl}$-doped specimen (doping level $>5 \mathrm{ppm}$ ). (b) EDS spectrum collected from the filament in (a). The O peak arises from the ice and the $\mathrm{C}$ is probably contamination. Full scale is 100 counts. The $\mathrm{Na}$ and $\mathrm{S}$ are probably impurities from the $\mathrm{KCl}$ dopant.

the grain boundary suggests that this is a possible mechanism whereby similar impurities could be concentrated into the grain boundaries as noted in both the Antarctic and Greenland ice cores (Cullen and Baker, 2000, 2001, 2002; Baker and Cullen, 2002, 2003; Barnes and others, 2002a, b, 2003; Baker and others, 2003, 2005; Obbard and others, 2003a, b, 2006a, b; Obbard and Baker, 2007).

\section{CONCLUSIONS}

The effects of small concentrations of solutes on the recrystallization and subsequent grain growth in ice single crystals have been investigated by extruding ice crystals through an ECAE jig, to impart substantial shear strain, and subsequently 'annealing' the crystals at $-3^{\circ} \mathrm{C}$. It was found that:

1. The migrating grain boundaries surrounding the newly recrystallized grains swept up impurities from the lattice, suggesting a mechanism whereby impurities could be concentrated into grain boundaries in ice cores, as is observed experimentally. Diffusion of the impurities to the grain boundary may also be at play, but significant accumulations of impurities at grain boundaries are unlikely to occur through this mechanism since very high diffusion rates will then be required.

2. Increasing the sulfuric acid concentration from 70 to $170 \mathrm{ppb}$ appears to retard the nucleation of new grains in the heavily strained ice single crystals and clearly decreases the grain boundary mobility. Sodium chloride, potassium chloride and magnesium sulfate also clearly decrease the grain boundary mobility, but not significantly until dopant concentrations of $\geq 5 \mathrm{ppm}$. These observations are indicative of how soluble impurities can control the grain size in ice cores.

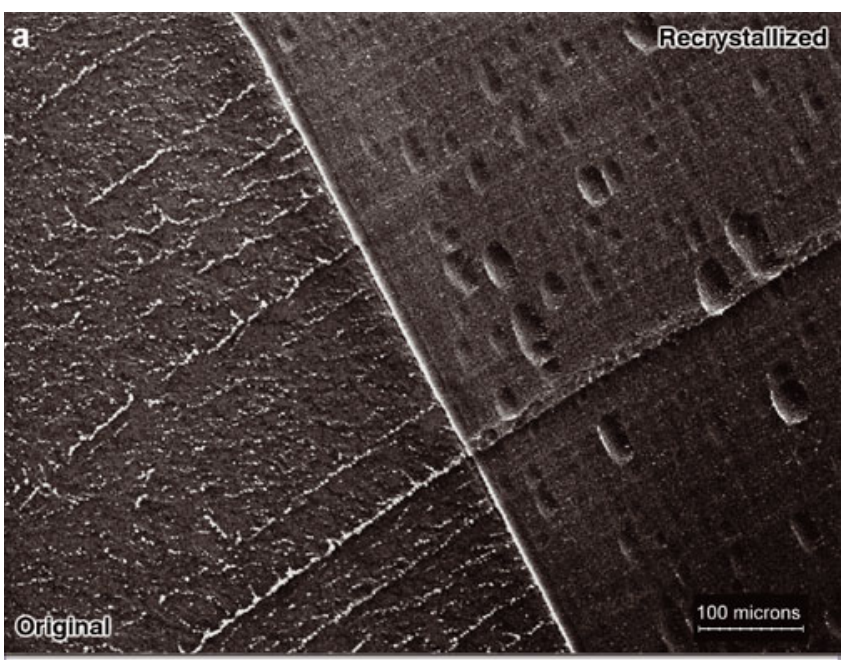

b

1527 Full Scale

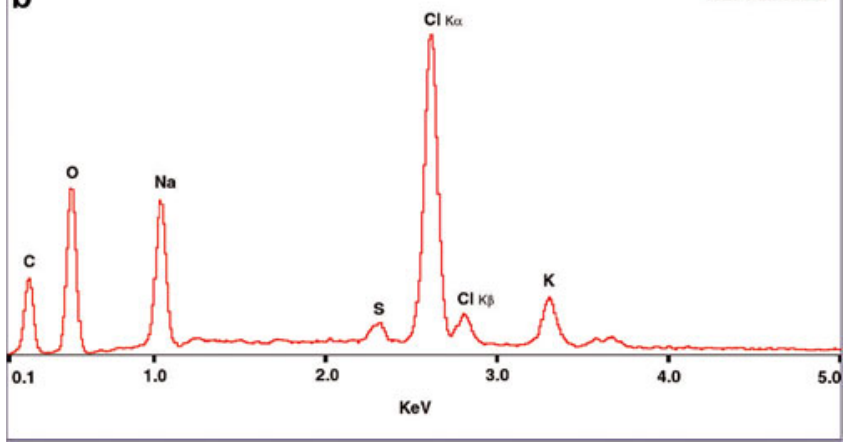

Fig. 12. (a) SEM image showing a high concentration of $\mathrm{NaCl}$ in the grain boundary between a newly formed grain and the original crystal. The specimen was subjected to ECAE at $-3^{\circ} \mathrm{C}$ and annealed at the same temperature. The concentration of $\mathrm{NaCl}$ in the original crystal was $5 \mathrm{ppm}$ which caused the heavily loaded grain boundary to stop moving shortly after the formation of the recrystallized grain (similar to the specimen in Fig. 5). (b) EDS spectrum collected from the grain boundary. The $\mathrm{O}$ peak arises from the ice, and the $\mathrm{C}$ is probably contamination. The $\mathrm{S}$ and $\mathrm{K}$ are probably from impurities in the $\mathrm{NaCl}$. Full scale is 100 counts.

3. Surprisingly, most lightly doped and undoped single crystals recrystallized to a new single crystal of a different orientation (five out of six $\mathrm{H}_{2} \mathrm{SO}_{4}$-doped specimens, three out of five $\mathrm{NaCl}$-doped specimens and one out of one freshwater specimen with the basal plane inclined at $45^{\circ}$ to the extrusion axis).

\section{ACKNOWLEDGEMENTS}

This research was supported by US National Science Foundation (NSF) grant OPP-0440523 and Army Research Office (ARO) grant DAAD 19-00-1-0444. The views and conclusions contained herein are those of the authors and should not be interpreted as representing official policies, either expressed or implied, of the ARO, NSF or the United States Government.

\section{REFERENCES}

Alley, R.B. and G.A. Woods. 1996. Impurity influence on normal grain growth in the GISP2 ice core, Greenland. J. Glaciol., 42(141), 255-260.

Alley, R.B., J.H. Perepezko and C.R. Bentley. 1986. Grain growth in polar ice: II. Application. J. Glaciol., 32(112), 425-433. 
Baker, I. and D. Cullen. 2002. The structure and chemistry of $94 \mathrm{~m}$ Greenland Ice Sheet Project 2 ice. Ann. Glaciol., 35, 224-230.

Baker, I. and D. Cullen. 2003. SEM/EDS observations of impurities in polar ice: artifacts or not? J. Glaciol., 49(165), 184-190.

Baker, I., D. Cullen and D. Iliescu. 2003. The microstructural location of impurities in ice. Can. J. Phys., 81(1-2), 1-9.

Baker, I., D. Iliescu, R. Obbard, H. Chang, B. Bostick and C.P. Daghlian. 2005. Microstructural characterization of ice cores. Ann. Glaciol., 42, 441-444.

Barnes, P.R.F., R. Mulvaney, K. Robinson and E.W. Wolff. 2002a. Observations of polar ice from the Holocene and the glacial period using the scanning electron microscope. Ann. Glaciol., 35, 559-566.

Barnes, P.R.F., R. Mulvaney, E.W. Wolff and K. Robinson. 2002b. A technique for the examination of polar ice using the scanning electron microscope. J. Microsc., 205(2), 118-124.

Barnes, P.R.F., E. Wolff, D.C. Mallard and H.M. Mader. 2003. SEM studies of the morphology and chemistry of polar ice. Microsc. Res. Tech., 62(1), 62-69.

Cullen, D. and I. Baker. 2000. Correspondence. The chemistry of grain boundaries in Greenland ice. J. Glaciol., 46(155), 703-706.

Cullen, D. and I. Baker. 2001. Observation of impurities in ice. Microsc. Res. Tech., 55(3), 198-207.

Cullen, D. and I. Baker. 2002. Observation of sulfate crystallites in Vostok accretion ice. Mater. Character., 48(4), 263-269.

De La Chapelle, S., O. Castelnau, V. Lipenkov and P. Duval. 1998. Dynamic recrystallization and texture development in ice as revealed by the study of deep ice cores in Antarctica and Greenland. J. Geophys. Res., 103(B3), 5091-5105.

Duval, P. and C. Lorius. 1980. Crystal size and climatic record down to the last ice age from Antarctic ice. Earth Planet. Sci. Lett., 48(1), 59-64.

Fukazawa, H., K. Sugiyama, S. Mae, H. Narita and T. Hondoh. 1998. Acid ions at triple junction of Antarctic ice observed by Raman scattering. Geophys. Res. Lett., 25(15), 2845-2848.

Glen, J.W. 1968. The effect of hydrogen disorder on dislocation movement and plastic deformation of ice. Phys. Kondens. Mater., 7(1), 43-51.

Gow, A.J. and T. Williamson. 1976. Rheological implications of the internal structure and crystal fabrics of the West Antarctic ice sheet as revealed by deep core drilling at Byrd Station. CRREL Rep. 76, 1665-1677.

Haessner, F. and S. Hofmann. 1978. Migration of high angle grain boundaries. In Haessner, F., ed. Recrystallization of metallic materials. Stuttgart, Dr. Riederer-Verlag GmbH, 63-96.

Iliescu, D. 2000. Contributions to the brittle compressive failure of ice. (PhD thesis, Dartmouth College.)

Iliescu, D., I. Baker and X. Li. 2003. The effects of sulfuric acid on the creep, recrystallization, and electrical properties of ice. Can. J. Phys., 81(1-2), 395-400.

Iwahashi, Y., J. Wang, Z. Horita, M. Nemoto and T.G. Langdon. 1996. Principle of equal-channel angular pressing for the processing of ultra-fine grained materials. Scripta Mater., 35(2), 143-146.

Kumai, M. and K.E. Francis. 1962. Nuclei in snow and ice crystals on the Greenland ice cap under natural and artificially stimulated conditions. J. Atmos. Sci., 19(6), 474-481.
Legrand, M. and P. Mayewski. 1997. Glaciochemistry of polar ice cores: a review. Rev. Geophys., 35(3), 219-243.

Libbrecht, K.G. 2005. The physics of snow crystals. Rep. Progr. Phys., 68(4), 855-895.

Lipenkov, V.Ya., N.I. Barkov, P. Duval and P. Pimienta. 1989. Crystalline texture of the $2083 \mathrm{~m}$ ice core at Vostok Station, Antarctica. J. Glaciol., 35(121), 392-398.

Michel, B. and R.O. Ramseier. 1971. Classification of river and lake ice. Can. Geotech. J., 8(1), 36-45.

Nasello, O.B., C.L. Di Prinzio and P.G. Guzmán. 2007. Grain boundary properties of ice doped with small concentrations of potassium chloride (KCl). J. Phys. Cond. Matter, 19, 246218. (10.1088/0953-8984/19/24/246218.)

Nye, J.F. 1998. Diffusion of isotopes in the annual layers of ice sheets. J. Glaciol., 44(148), 467-468.

Obbard, R. and I. Baker. 2007. The microstructure of meteoric ice from Vostok, Antarctica. J. Glaciol., 53(180), 41-62.

Obbard, R., D. Iliescu, D. Cullen and I. Baker. 2003a. SEM/EDS comparison of polar and seasonal temperate ice. Microsc. Res. Tech., 62(1), 49-61.

Obbard, R., D. Iliescu, I. Baker and D. Cullen. 2003b. A technique for the scanning electron microscopy and microanalysis of uncoated ice crystals. In Weertman, J.R., M. Fine, K. Faber, W. King and P. Liaw, eds. Electron microscopy: its role in materials science (The Mike Meshii Symposium). Warrendale, PA, American Institute of Mining, Metallurgical, and Petroleum Engineers. The Metals, Minerals and Materials Society, 133-140.

Obbard, R., I. Baker and D. Iliescu. 2006a. Correspondence. Grain boundary grooving in ice in a scanning electron microscope. J. Glaciol., 52(176), 169-172.

Obbard, R., I. Baker and K. Sieg. 2006b. Using electron backscatter diffraction patterns to examine recrystallization in polar ice sheets. J. Glaciol., 52(179), 546-557.

Segal, V.M. 1995. Materials processing by simple shear. Mater. Sci. Eng. A, 197(2), 157-164.

Segal, V.M., V.I. Reznikov, A.E. Drobyshevskiy and V.I. Kopylov. 1981. Plastic working of metals by simple shear. Russ. Metall. 1, 99-105.

Thorsteinsson, T., J. Kipfstuhl, H. Eicken, S.J. Johnsen and K. Fuhrer. 1995. Crystal size variations in Eemian-age ice from the GRIP ice core, central Greenland. Earth Planet. Sci. Lett., 131(3-4), 381-394.

Thorsteinsson, T., J. Kipfstuhl and H. Miller. 1997. Textures and fabrics in the GRIP ice core. J. Geophys. Res., 102(C12), 26,583-26,599.

Trickett, Y.L., I. Baker and P.M.S. Pradhan. 2000. The effects of sulfuric acid on the mechanical properties of ice single crystals. J. Glaciol., 46(153), 239-243.

Whitworth, R.W. 1980. The influence of the choice of glide plane on the theory of the velocity of dislocations in ice. Philos. Mag., 41(4), 521-525.

Whitworth, R.W., J.G. Paren and J.W. Glen. 1976. The velocity of dislocations in ice: a theory based on proton disorder. Philos. Mag., 33(3), 409-426.

Wolff, E.W., R. Mulvaney and K. Oates. 1988. The location of impurities in Antarctic ice. Ann. Glaciol., 11, 194-197.

$\mathrm{Wu}, \mathrm{Y}$. and I. Baker. 1997. An experimental study of equal channel angular extrusion. Scripta Metall. Mater., 37(4), 437-442. 